\title{
The Status of the Fourth Ventricle and Ambient Cisterns Predict Outcome in Moderate and Severe Traumatic Brain Injury
}

\author{
Bram Jacobs, ${ }^{1}$ Tjemme Beems, ${ }^{2}$ Ton M. van der Vliet, ${ }^{3}$ George F. Borm, ${ }^{4}$ and Pieter E. Vos ${ }^{1}$
}

\begin{abstract}
Computed tomography (CT) of the head has become the diagnostic tool of choice, particularly for moderate and severe traumatic brain injury (TBI). Various CT characteristics are associated with outcome, and may therefore be used as outcome predictors. One of the most prominent predictors appears to be the status of the basal cisterns. This study describes the prognostic value of the appearance of individual cisterns and ventricles in relation to that of the basal cisterns. Further, we determine the interrater and intrarater reliability in the evaluation of the cisterns and ventricles. All consecutive moderate and severe adult TBI patients admitted to our hospital were included in this study as part of the prospective Radboud University Brain Injury Cohort Study (RUBICS). Outcome was assessed at 6 months post-trauma using the Glasgow Outcome Scale-Extended (GOS-E). The predictive value of cisterns and ventricles was determined using multivariate binary logistic regression analysis. We included 126 moderate and 574 severe TBI patients. Absence (complete obliteration), but also compression of the ambient cisterns and/or the fourth ventricle were strongly related to unfavorable outcome and death and emerged as the only significant outcome predictors after multivariate analysis. The assessment of the ambient cisterns and the fourth ventricle had a satisfactory inter- and intrarater reliability (kappa coefficients: 0.80-0.95). We conclude that, because obliteration of the ambient cisterns and the fourth ventricle both are better than the status of the basal cisterns as outcome predictors, they might be used in CT prediction models in cases of moderate and severe TBI.
\end{abstract}

Key words: cisterns; computed tomography scan; head injury; outcome; severe traumatic brain injury; ventricles

\section{Introduction}

C OMPUTED TOMOgRaphy (CT) SCANNING of the head has become the principal diagnostic tool in traumatic brain injury (TBI) since its introduction in 1971 (Metting et al., 2007). Today, a head CT scan is performed routinely, especially in the acute phase of moderate and severe TBI, but also in a large proportion of mild TBI patients. It is used to identify traumatic cranial and intracranial abnormalities requiring immediate neurosurgical intervention or extensive monitoring. Further, it has been acknowledged that CT characteristics are associated with outcome after moderate to severe TBI, and it may therefore be used to predict outcome (Maas et al., 2005, 2007; The American Association of Neurological Surgeons, 2000).

One of the most prominent CT characteristics that has emerged as a powerful predictor of outcome is the appearance of the basal cisterns. Although most studies use the term "perimesencephalic cisterns" when referring to the basal cisterns, no clear definition exists to delineate the basal cisterns (The American Association of Neurological Surgeons, 2000). Compression or absence of the basal cisterns is strongly associated with adverse outcome in severe TBI, resulting in a two- to fourfold increase in mortality or unfavorable outcome compared to patients with normal basal cisterns (Colquhoun and Burrows, 1989; Eisenberg et al., 1990; Liu et al., 1995; Maas et al., 2005, 2007; Selladurai et al., 1992; Toutant et al., 1984; van Dongen et al., 1983). Moreover, complete and partially obliterated basal cisterns are considered a sign of raised intracranial pressure (ICP) (Colquhoun and Burrows, 1989; Teasdale et al., 1984; Toutant et al., 1984). However, in some studies of outcome in moderate and severe TBI, the status of the basal cisterns was not found to be an independent predictor (Lannoo et al., 2000; Signorini et al., 1999a, 1999b). One explanation might be that in these studies absent pupil

${ }^{1}$ Department of Neurology, ${ }^{2}$ Department of Neurosurgery, ${ }^{3}$ Department of Radiology, and ${ }^{4}$ Department of Epidemiology, Biostatistics and HTA, Radboud University Nijmegen Medical Centre, Nijmegen, The Netherlands. 
reactivity proved to be an outcome predictor, and a strong association has been found between the status of the basal cisterns and pupil reactivity (Teasdale et al., 1984; van Dongen et al., 1983).

The status of the perimesencephalic cisterns is also used to classify TBI. In the widely recognized Traumatic Coma Data Bank (TCDB) CT classification it is an essential classification criterion (Marshall et al., 1991). The TCDB CT classification categorizes TBI patients into six groups. The primary distinction is made between diffuse injury (category I-IV) and the presence of mass lesions (evacuated or non-evacuated). Within the diffuse injury category, patients are partially differentiated based on the presence, compression, or absence of the perimesencephalic cisterns. The TCDB CT classification is used to describe CT abnormalities and to stratify patients in research trials and prognostic studies (Cremer et al., 2006; Hukkelhoven et al., 2005, 2006; Maas et al., 2007; Marmarou et al., 2007; Murray et al., 2007; Steyerberg et al., 2008). Various authors have elaborated on the aspect of the basal cisterns, but to our knowledge, no systematic evaluation of the predictive value of the individual cisterns has been performed, as has been noted before (The American Association of Neurological Surgeons, 2000).

Research on the predictive value of the cerebral ventricles in TBI has not been as extensive as that done on the basal or perimesencephalic cisterns. Studies focusing on the third ventricle showed an association between a compressed or absent third ventricle and raised ICP and adverse outcome after severe TBI (Colquhoun and Burrows, 1989; Teasdale et al., 1984). Recently, obliteration of the third ventricle was identified as a prognostic variable (odds ratio of unfavorable outcome: 2.2) in a multivariate predictive model of TBI (Perel et al., 2008). Other studies, however, did not select the status of the ventricles as an outcome predictor in a multivariable model (van Dongen et al., 1983; Wardlaw et al., 2002), or did not find predictive power for small or asymmetrical ventricles (Eisenberg et al., 1990). Determining the status of the basal cisterns and ventricles on CT by visual inspection is susceptible to interobserver variation; however, adequate data on inter- and intrarater variability are not available (The American Association of Neurological Surgeons, 2000).

The aim of this study is to determine the prognostic value of the status of the various individual cisterns and ventricles as identified with CT scanning in a prospective cohort of consecutive moderate and severe TBI patients. Furthermore, to select independent predictors of functional outcome, we compare the cisterns and ventricles in a multivariate analysis. Finally, we determine the interobserver variation and intrarater reliability in the assessment of the status of the cisterns and ventricles.

\section{Methods}

\section{Subjects}

We obtained the data for this study from the Radboud University Brain Injury Cohort Study (RUBICS), which is an ongoing prospective observational cohort begun on January 1 , 1998. All consecutive patients, including children, with a diagnosis of mild, moderate, and severe TBI admitted to the emergency department (ED) of the Radboud University Nijmegen Medical Centre, a level I trauma center in the eastern Netherlands, are included in the cohort. All patients with moderate and severe TBI, aged 16 years and older, admitted to the ED of our hospital between January 1998 and January 2006 were selected from the RUBICS database. Moderate TBI was defined by a Glasgow Coma Scale (GCS) score in the ED of 9-12 after initial resuscitation, or an admission GCS of 9-12 followed by sedation and intubation during resuscitation for a non-neurological cause. Severe TBI was characterized by an ED GCS score of $\leq 8$ after resuscitation, preferably obtained before sedation and intubation. We focused on closed head injury cases, because penetrating head injuries may disturb the aspect of the cerebrospinal fluid (CSF) spaces too much to allow analysis. The RUBICS databank comprises demographic data, clinical and radiological injury variables, and outcome scores. Several CT characteristics and the TCDB CT classification are also recorded (Marshall et al., 1991).

\section{Outcome assessment}

Outcome was assessed at 6 months post-injury using the Glasgow Outcome Score-Extended (GOS-E) (Wilson et al., 1998). The 6-month time-frame was chosen because a large majority of severe TBI patients improves to their final functional outcome level, as assessed using the GOS-E, during the first 6 months post-injury (Choi et al., 1994). The GOS-E is an 8-point scale expressing functional outcome, ranging from 1 : death, to 8: complete recovery. GOS-E scores of $\leq 4$ were considered unfavorable outcomes and were dichotomized as such. If no outcome could be obtained directly from the patient, charts and correspondence were reviewed to determine outcome and construct a GOS-E score. Patients with no outcome score or outcome data insufficient to determine the GOS-E score were considered lost to follow-up.

\section{Computed tomography}

After initial resuscitation all patients underwent a CT scan of the head. Only the initial CT scans of patients admitted to the hospital within $24 \mathrm{~h}$ after sustaining the head injury were analyzed in this study. CT was performed in the axial plane with slices scanned parallel to the orbito-meatal line. Before 2002 slice thickness was $4.5 \mathrm{~mm}$ infratentorial and $6.0 \mathrm{~mm}$ supratentorial; from 2002 on $5.0-\mathrm{mm}$ reconstructions were made out of $0.75-\mathrm{mm}$ slices in both the supratentorial and infratentorial regions. Contrast-enhanced CT was not used on a routine basis. Each CT scan was scored by one of three raters (B.J., T.B., and P.E.V.), using a predefined structured format as previously described (Jacobs, 2009, epub). In short, abnormalities like intracranial hematomas, traumatic subarachnoid hemorrhage, fractures, and the appearance of cisterns and ventricles were registered on data entry sheets and subsequently entered into the computer. In addition, all scans were classified according to the TCDB CT classification (Marshall et al., 1991). For this study we used the data collected about the status (presence, compression, or absence) of cisterns and ventricles (Fig. 1): foramen magnum, cerebello-medullary cistern, fourth ventricle, prepontine cistern, chiasmatic or suprasellar cistern (pentagon), ambient cisterns (left and right), quadrigeminal cistern, third ventricle and lateral ventricles (left and right), and the sylvian fissures (left and right).

All cisterns and ventricles were scored by visual inspection using a three point scale: $1=$ normal, indicating normal anatomy; 2 = compressed, indicating unilateral narrowing of a cistern or ventricle (a slit-like appearance), but CSF still is 


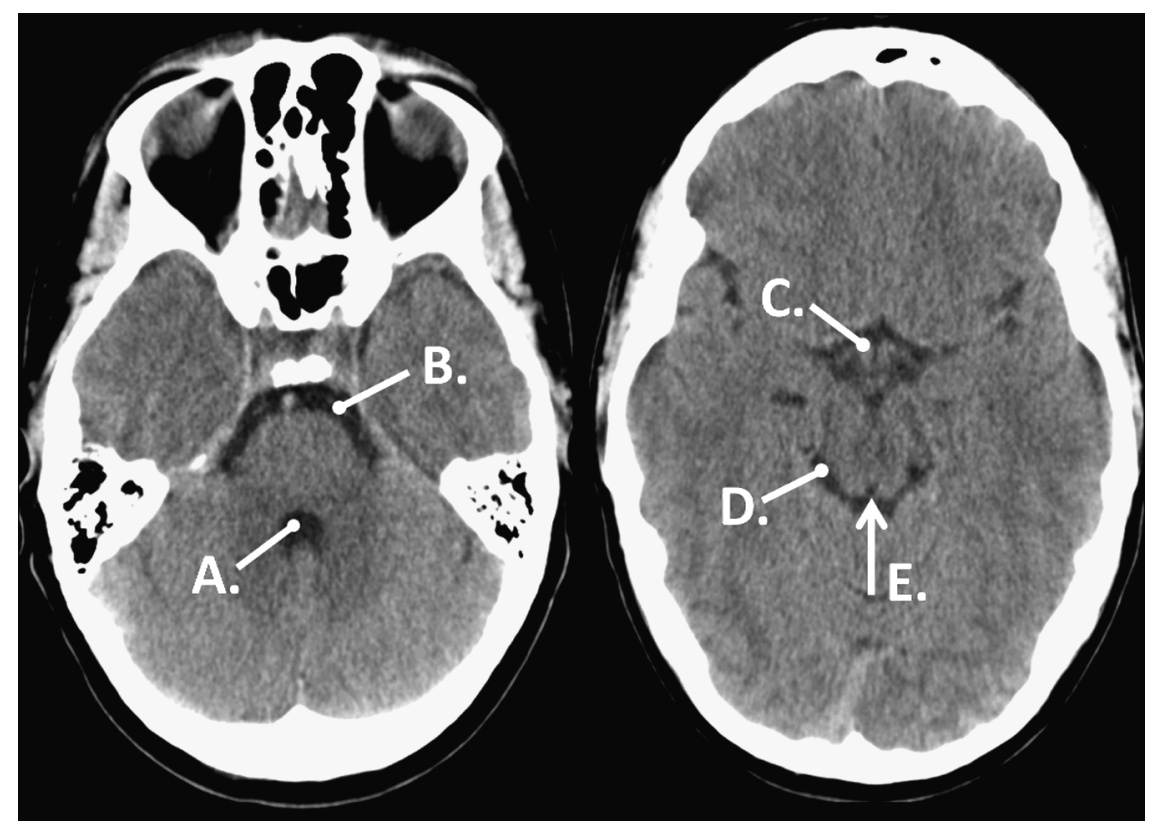

FIG. 1. Normal cisterns and fourth ventricle. CT scan of the head in a 27-year-old patient that suffered a mild TBI. (A) Fourth ventricle. (B) Prepontine cistern. (C) Pentagon (suprasellar) cistern. (D) Right ambient cistern. (E) Quadrigeminal cistern (lower portion).

visible; and $3=$ absent, indicating no CSF is visible. In addition a binary score was computed for all cisterns and ventricles: "normal" or "abnormal." The scores of the left and right ambient cistern were combined to form a comprised ambient cistern score, in which the worst score of the left or the right side was used as the new ambient cistern score. In addition, a basal mesencephalic cistern score was quantified by combining the scores for the ambient cisterns, the pentagon (suprasellar) cistern, and the quadrigeminal cistern. This definition of the basal cisterns has also been used by other authors (Chen et al., 2009; Colquhoun and Burrows, 1989).

\section{Statistical analysis}

We used univariate and multivariate binary logistic regression analysis to identify the abnormalities in cistern and ventricle anatomy that were most strongly associated with an adverse outcome after moderate to severe TBI. Missing data were excluded from the analysis. As a dependent variable we dichotomized the 6-month GOS-E into unfavorable (GOS-E 1-4), and favorable (GOS-E 5-8), and also into death (GOS-E 1 ) or survival (GOS-E 2-8). First, all the variables (3-point scale scores and binary scores) were analyzed univariately to determine which of these CT characteristics was associated with unfavorable outcome and/or death. Second, significant predictors $(p<0.01)$ were analyzed multivariately, using the forward stepwise likelihood ratio method, to determine which combination of these variables independently predicted adverse outcome at 6-months after moderate to severe TBI. We performed three successive multivariate analyses. One multivariate analysis was done using only the 3-point scale scores, one analysis included only the binary scores, and a third combined the 3-point scale and the binary scores. To determine which of these three combinations of predictors had the best performance, the C-statistic was calculated. In order to avoid having irrelevant differences be statistically significant due to the large number of observations, we used a two-sided $p$-value of 0.01 as the criterion for significance in the logistic regression analyses.

To determine the interrater reliability of the scoring of the cisterns and the ventricular system, we randomly selected 73 CT scans from the RUBICS database (including mild TBI) to be scored by two observers (B.J. and P.E.V.). The interobserver variation of the 3-point scale scores was determined using a linear weighted kappa analysis, and for the dichotomized scores we used the Cohen's unweighted kappa method. Further, $68 \mathrm{CT}$ scans were selected at random to determine the intrarater variation of one observer (P.E.V.), using the unweighted or linear weighted kappa analysis where applicable.

\section{Results}

We included 700 consecutive patients: 126 moderate and 574 severe TBI patients. Accurate CT data were available for 658 patients (121 moderate and 537 severe). Survival data were available for 605 patients, and data were available for 567 patients about the prediction of unfavorable outcome (complete GOS-E data). The inclusion flow chart of the study and the reasons for exclusion are shown in Figure 2.

Several demographic, clinical, and outcome characteristics of the patient sample $(n=700)$ are shown in Table 1 . Demographic and clinical data were missing in fewer than $0.5 \%$ of these patients. For all CT characteristics, fewer than $2.1 \%$ of the required values were missing. We studied a predominantly male population (71\%) with a mean age of 43.8 years. The main cause of traumatic injury was a traffic-related crash in severe TBI $(70 \%)$ patients, and resulted from a fall in those with moderate TBI $(40 \%)$. In $71(12 \%)$ of the severe TBI patients, neurosurgical intervention (the placing of an ICP monitoring device was not regarded as such) was necessary 


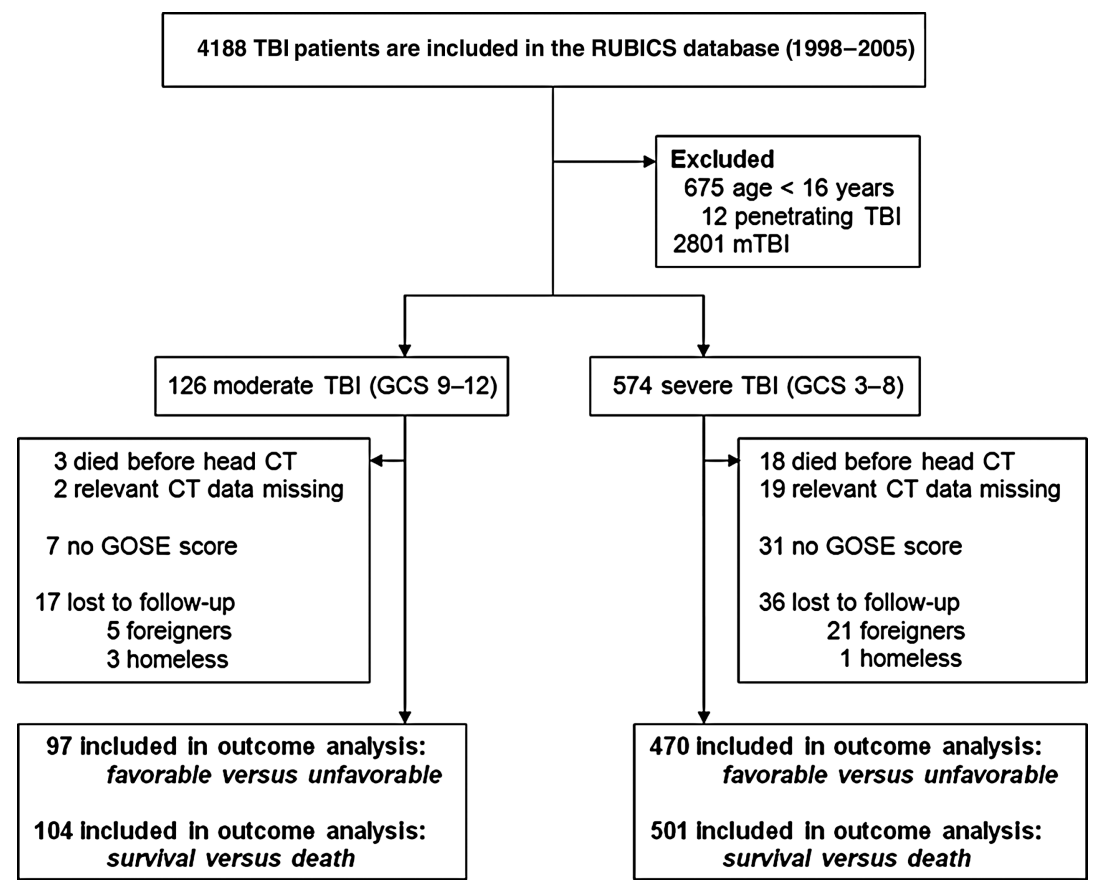

FIG. 2. Diagram showing the inclusion and exclusion criteria of the patients examined in the study (TBI, traumatic brain injury; RUBICS, Radboud University Nijmegen Brain Injury Cohort Study; mTBI: mild traumatic brain injury; GCS, Glasgow Coma Scale score; CT, computed tomography; GOSE, Glasgow Outcome Scale-Extended).

Table 1. Patient Demographic and Clinical Characteristics At Presentation

\begin{tabular}{|c|c|c|}
\hline Characteristic & $\begin{array}{l}\text { Moderate TBI } \\
\quad(\mathrm{n}=126)\end{array}$ & $\begin{array}{c}\text { Severe TBI } \\
(\mathrm{n}=574)\end{array}$ \\
\hline Male gender, no. (\%) & $77(61.1)$ & $419(73.0)$ \\
\hline Age, mean (SD) & $47.7(22.3)$ & $42.9(19.9)$ \\
\hline \multicolumn{3}{|l|}{ Trauma mechanism } \\
\hline Traffic-related crash, no. (\%) & $60(47.6)$ & $403(70.2)$ \\
\hline Fall, no. (\%) & $50(39.7)$ & $123(21.4)$ \\
\hline Sports-related, no. (\%) & $3(2.4)$ & $12(2.1)$ \\
\hline Violence, no. (\%) & $5(4.0)$ & 11 (1.9) \\
\hline Suicide, no. (\%) & $4(3.2)$ & $7(1.2)$ \\
\hline Other/missing, no. (\%) & $4(3.2)$ & $18(3.1)$ \\
\hline $\begin{array}{l}\text { GCS at ED admission, } \\
\text { median (range) }\end{array}$ & $11(9-12)$ & $3(3-8)$ \\
\hline AIS head, mean (SD) & $3.5(1.1)$ & $4.3(4.1)$ \\
\hline ISS, mean (SD) & $20.5(12.6)$ & $31.6(14.8)$ \\
\hline Hypotensive episode, no. (\%) & $7(5.6)$ & $133(23.2)$ \\
\hline Hypoxic episode, no. (\%) & $12(9.5)$ & $165(28.7)$ \\
\hline \multicolumn{3}{|l|}{ Pupillary response } \\
\hline Present, no. (\%) & $117(92.9)$ & $374(65.2)$ \\
\hline One side absent, no. (\%) & $6(4.8)$ & $74(12.9)$ \\
\hline Bilateral absent, no. (\%) & $3(2.4)$ & $126(22.0)$ \\
\hline Neurosurgical intervention & $12(9.5)$ & $71(12.4)$ \\
\hline \multicolumn{3}{|l|}{ Outcome } \\
\hline Death (GOSE score 1) & $29(23.0)$ & $222(38.7)$ \\
\hline Missing & $16(12.7)$ & $39(6.8)$ \\
\hline Unfavorable (GOSE score 1-4) & $39(31.0)$ & $289(50.3)$ \\
\hline Missing & $25(19.8)$ & $71(12.4)$ \\
\hline
\end{tabular}

mTBI, mild traumatic brain injury; GCS, Glasgow Coma Scale; ED, emergency department; AIS, Abbreviated Injury Scale score; ISS, Injury Severity Score; GOSE, Glasgow Outcome Scale-Extended; SD, standard deviation. (craniotomy for acute subdural hematoma [SDH], $n=38$; epidural hematoma [EDH], $n=22$; hemorrhagic contusion, $n=7$; compression fracture, $n=4)$. In those with moderate TBI, $12(10 \%)$ patients required neurosurgical intervention (SDH, $n=6 ; \mathrm{EDH}, n=5$; hemorrhagic contusion, $n=1$ ). A total of $29(23 \%)$ patients died after moderate TBI, and 222 patients died (39\%) after severe TBI.

Table 2 shows the patient distribution over the different categories of the TCDB CT classification.

Intracranial abnormalities were found in $433(81 \%)$ of the severe TBI, and in $73(60 \%)$ of the moderate TBI patients. In $47 \%$ of the severe TBI and $28 \%$ of the moderate TBI patients the basal mesencephalic cisterns were abnormal (i.e., compressed or absent).

Univariate binary logistic regression analysis showed that the status of all cisterns and ventricles was significantly $(p<0.01)$ associated with both unfavorable outcome and death after moderate to severe TBI (Tables 3A and B and 4A and $B$ ); the results of the cerebello-medullary cistern, left and right ambient cisterns, sylvian fissures, and the lateral ventricles are not shown.

Univariate analysis of the GCS, one of the classical and established outcome predictors in TBI, resulted in an odds ratio (OR) of 0.8 (99\% confidence interval [CI]: 0.77-0.9; $p<0.0001)$ in death, and 0.85 (99\% CI: 0.8, 0.9) in unfavorable outcome.

First, multivariate logistic regression analysis (forward L.R. method) of all the 3-point scale (normal, compressed, or absent) scores showed that the status of the fourth ventricle and the ambient cisterns were independent predictors of death after moderate to severe TBI (Tables 5A, B, and C). When the dichotomized (normal or abnormal) scores were analyzed, 
Table 2. Incidence of CT Abnormalities on Initial Head CT and Distribution of Patients according to the Traumatic Coma Data Bank CT Classification

\begin{tabular}{lcr}
\hline CT characteristics & Moderate TBI $(\mathrm{n}=121)$ & Severe TBI $(\mathrm{n}=537)$ \\
\hline Intracranial abnormalities, no. (\%) & $73(60.3)$ & $433(80.6)$ \\
CT abnormalities (intracranial and fractures), no. (\%) & $75(62.0)$ & $439(81.8)$ \\
TCDB classification & & \\
Diffuse injury I, no. (\%) & $48(39.7)$ & $104(19.4)$ \\
Diffuse injury II, no. (\%) & $38(31.4)$ & $156(29.1)$ \\
Diffuse injury III, no. (\%) & $5(4.1)$ & $88(16.4)$ \\
Diffuse injury IV, no. (\%) & 0 & $17(3.2)$ \\
Evacuated mass lesion/neurosurgical intervention, no. (\%) & $12(9.9)$ & $71(13.2)$ \\
Non-evacuated mass lesion, no. (\%) & $18(14.9)$ & $101(18.8)$ \\
\hline
\end{tabular}

$\mathrm{CT}$, computed tomography; TBI, traumatic brain injury; TCDB, Traumatic Coma Data Bank.

again obliteration of the fourth ventricle and ambient cisterns proved to be outcome predictors (Table 5B). After a multivariate test of all 3-point scales and dichotomized scores simultaneously, the dichotomized score of the fourth ventricle and the 3-point scale score of the ambient cisterns emerged as significant predictors of death (Table 5C). The same procedure was followed with unfavorable outcome instead of death as the dependent variable (Tables 6A, B, and C). The results were comparable to a large extent, but there was with one exception. In the multivariate analysis of the 3-point scale scores only the status of the ambient cisterns was associated with an unfavorable outcome (Table 6A). The GCS did not show a significant relation with outcome when we finally re-ran the different multivariate analyses of the cistern and ventricle scores including the GCS. The ORs of the fourth ventricle and ambient cistern scores were therefore not altered.

Figure 3 depicts the mortality rates in the various patient categories with normal, compressed, or absent fourth ventricle, ambient cisterns, and basal cisterns.

The C-statistics of the three combinations were comparable in both dead-three-point scales: 0.80; dichotomous scores: 0.79 ; combined: 0.80 , and unfavorable outcometrichotomous variables: 0.77 ; dichotomous variables: 0.76 ; and combined: 0.76 .

The interrater kappa coefficients of the status of the fourth ventricle were 0.93 (normal versus abnormal), and 0.95 (normal, compressed, or absent), and of the ambient cisterns ( 0.80 and 0.81 , respectively). The intrarater analysis showed kappa coefficients of the dichotomized fourth ventricle score (normal versus abnormal) of 0.89 ; of the 3-point scale (normal, compressed, or absent): 0.80; and of the ambient cisterns, normal versus abnormal: 0.83 , and normal, compressed, or absent: 0.80 .

\section{Discussion}

This study shows that from all cisterns, ventricles, and the sylvian fissures, as visualized by head CT scanning, the status of the fourth ventricle and the ambient cisterns are independent predictors of death and unfavorable functional outcome at 6 months post-trauma in moderate and severe TBI patients. We also demonstrate that the interobserver agreement and intrarater reliability for these CT characteristics are adequate.

The findings of our study are consistent with present knowledge that the status of the basal, in other studies re- ferred to as perimesencephalic, cisterns is an important aspect of the head CT exam, and is a predictor of functional outcome in moderate and severe TBI patients (Colquhoun and Burrows, 1989; Eisenberg et al., 1990; Liu et al., 1995; Maas et al., 2005; Maas et al., 2007; Selladurai et al., 1992; Toutant et al., 1984; van Dongen et al., 1983). Absent basal cisterns, as opposed to a normal aspect of the basal cisterns, increased mortality in our study almost fivefold: $76.7 \%$ versus $16.4 \%$ (Fig. 3). However, when the basal cisterns were analyzed multivariately, simultaneously with the other cisterns and ventricles, they did not emerge as an independent outcome predictor. In our study the ambient cisterns, a part of the basal perimesencephalic cisterns, were the strongest predictor of outcome. The predictive value of these cisterns has not been examined as a sole entity in detail before. The same holds true for the fourth ventricle, the second independent predictor we identified. The strong association of the fourth ventricle with outcome might be explained by the fact that as a midline structure, compression indicates more brain shift due to a higher ICP, or the presence of a larger intracranial mass lesion, than that seen with unilateral obliteration of other cisterns or ventricles. Alternatively, when contusion, hematoma, or edema are present within the brainstem, narrowing of the fourth ventricle may occur before obliteration of, for example, the perimensencephalic or prepontine cisterns. Finally, compression of the fourth ventricle will frequently be accompanied by deformation of the brainstem, probably more often than (unilateral) compression of the perimesencephalic cisterns. A deformed brainstem is associated with increased mortality compared to a normal brainstem with obliteration of the perimesencephalic cisterns (Liu et al., 1995). Analogous to this, when the fourth ventricle is compressed, the brainstem is likely to be deformed as well: the status of the fourth ventricle may thus be considered a surrogate marker for brainstem integrity.

In our study, the status of the third ventricle was univariately associated with outcome; however, it proved to be one of the weakest predictors. After multivariate analysis, the third ventricle lost its predictive value, confirming findings by others (van Dongen et al., 1983; Wardlaw et al., 2002), but contradicting studies that emphasize the predictive value of the third ventricle (Colquhoun and Burrows, 1989; Perel et al., 2008; Teasdale et al., 1984). Interestingly, in those studies accentuating the contribution of the third ventricle, the status of the basal cisterns and third ventricle were combined to form 
Table 3A. Association of Cistern and Ventricle Status (Trimodal) With Death $(\mathrm{N}=605)$ AFTER Univariate ANALYsis

\begin{tabular}{|c|c|c|c|}
\hline Cistern/ventricle (n) & OR & $99 \% \mathrm{CI}$ & p Value \\
\hline \multicolumn{4}{|l|}{ Foramen magnum } \\
\hline Normal (474) & ref. & & \\
\hline Compressed (72) & 5.8 & $(2.9-11.7)$ & $<0.0001$ \\
\hline Absent (47) & 24.5 & $(7.0-85.4)$ & $<0.0001$ \\
\hline \multicolumn{4}{|l|}{ Fourth Ventricle } \\
\hline Normal (459) & ref. & & \\
\hline Compressed (87) & 10.0 & $(5.0-20.0)$ & $<0.0001$ \\
\hline Absent (46) & 27.6 & $(7.9-96.8)$ & $<0.0001$ \\
\hline \multicolumn{4}{|l|}{ Prepontine cistern } \\
\hline Normal (404) & ref. & & \\
\hline Compressed (116) & 6.4 & $(3.6-11.5)$ & $<0.0001$ \\
\hline Absent (73) & 18.7 & $(8.0-43.8)$ & $<0.0001$ \\
\hline \multicolumn{4}{|l|}{ Pentagon } \\
\hline Normal (388) & ref. & & \\
\hline Compressed (89) & 3.3 & $(1.7-6.2)$ & $<0.0001$ \\
\hline Absent (116) & 17.3 & $(8.6-34.5)$ & $<0.0001$ \\
\hline \multicolumn{4}{|l|}{ Cisterna ambiens } \\
\hline Normal (343) & ref. & & \\
\hline Compressed (132) & 4.3 & $(2.4-7.8)$ & $<0.0001$ \\
\hline Absent (118) & 26.2 & $(12.5-54.9)$ & $<0.0001$ \\
\hline \multicolumn{4}{|l|}{ Quadrigeminal cistern } \\
\hline Normal (392) & ref. & & \\
\hline Compressed (88) & 5.1 & $(2.7-9.6)$ & $<0.0001$ \\
\hline Absent (112) & 12.1 & $(6.3-23.1)$ & $<0.0001$ \\
\hline \multicolumn{4}{|l|}{ Third ventricle } \\
\hline Normal (402) & ref. & & \\
\hline Compressed (63) & 1.9 & $(0.9-3.9)$ & 0.032 \\
\hline Absent (128) & 11.8 & $(7.9-96.8)$ & $<0.0001$ \\
\hline \multicolumn{4}{|c|}{ Basal mesencephalic cisterns } \\
\hline Normal (323) & ref. & & \\
\hline Compressed (120) & 2.8 & $(1.5-5.3)$ & $<0.0001$ \\
\hline Absent (150) & 16.7 & $(8.9-31.4)$ & $<0.0001$ \\
\hline
\end{tabular}

OR, odds ratio; $\mathrm{CI}$, confidence interval; ref., reference.

Table 3B. Association of Cistern and Ventricle Status (Bimodal) With DeAth $(\mathrm{N}=605)$ AFTER Univariate ANAlysis

\begin{tabular}{|c|c|c|c|}
\hline Cistern/ventricle (n) & $O R$ & $99 \% C I$ & $\mathrm{p}$ \\
\hline $\begin{array}{l}\text { Foramen magnum- } \\
\text { abnormal (119) }\end{array}$ & 9.1 & $(4.9-16.7)$ & $<0.0001$ \\
\hline $\begin{array}{l}\text { Fourth ventricle- } \\
\text { abnormal (133) }\end{array}$ & 13.2 & $(7.1-24.7)$ & $<0.0001$ \\
\hline $\begin{array}{l}\text { Prepontine cistern- } \\
\text { abnormal (189) }\end{array}$ & 9.1 & $(5.4-15.4)$ & $<0.0001$ \\
\hline Pentagon-abnormal (205) & 7.6 & $(4.6-12.6)$ & $<0.0001$ \\
\hline $\begin{array}{l}\text { Cisterna ambiens- } \\
\text { abnormal (250) }\end{array}$ & 9.0 & $(5.4-15.0)$ & $<0.0001$ \\
\hline $\begin{array}{l}\text { Quadrigeminal cistern- } \\
\text { abnormal (200) }\end{array}$ & 8.0 & $(4.8-13.2)$ & $<0.0001$ \\
\hline $\begin{array}{l}\text { Third ventricle- } \\
\text { abnormal (191) }\end{array}$ & 6.0 & $(3.6-9.8)$ & $<0.0001$ \\
\hline $\begin{array}{l}\text { Basal mesencephalic } \\
\text { cisterns-abnormal (270) }\end{array}$ & 7.2 & $(4.4-11.9)$ & $<0.0001$ \\
\hline
\end{tabular}

OR, odds ratio; $\mathrm{CI}$, confidence interval.

Table 4A. Association of Cistern and Ventricle Status (Trimodal) With Unfavorable Outcome $(\mathrm{N}=567)$ AFTer UnIVARIATE ANALysis

Cistern/ventricle (n) OR $\quad$ OR $\mathrm{CI} \quad \mathrm{p}$

Foramen magnum

Normal (439)

Compressed (71)

Absent (47)

Fourth ventricle

Normal (425)

Compressed (85)

Absent (46)

Prepontine cistern

Normal (369)

Compressed (115)

Absent (73)

Pentagon

Normal (354)

Compressed (87)

Absent (116)

Cisterna ambiens

Normal (311)

Compressed (129)

Absent (117)

Quadrigeminal cistern

Normal (358)

Compressed (87)

Absent (111)

Third ventricle

Normal (368)

Compressed (63)

Absent (126)

Basal mesencephalic cisterns

Normal (292)

Compressed (116)

Absent (149)

OR, odds ratio; $\mathrm{CI}$, confidence interval; ref., reference.

Table 4B. Association of Cistern and Ventricle Status (Bimodal) With Unfavorable Outcome $(\mathrm{N}=567)$ AFTER UNIVARIATE ANALYsis

\begin{tabular}{lccc}
\hline Cistern/ventricle (n) & OR & $99 \%$ CI & $\mathrm{p}$ \\
\hline $\begin{array}{l}\text { Foramen magnum- } \\
\quad \text { abnormal (118) }\end{array}$ & 11.2 & $(5.0-24.8)$ & $<0.0001$ \\
$\begin{array}{l}\text { Fourth ventricle- } \\
\quad \text { abnormal (131) }\end{array}$ & 13.5 & $(6.1-29.8)$ & $<0.0001$ \\
$\begin{array}{l}\text { Prepontine cistern- } \\
\text { abnormal (188) }\end{array}$ & 7.9 & $(4.5-13.8)$ & $<0.0001$ \\
$\begin{array}{l}\text { Pentagon-abnormal (203) } \\
\begin{array}{l}\text { Cisterna ambiens- } \\
\quad \text { abnormal (246) }\end{array}\end{array}$ & 7.1 & $(4.1-12.0)$ & $<0.0001$ \\
$\begin{array}{l}\text { Quadrigeminal cistern- } \\
\quad \text { abnormal (198) }\end{array}$ & 7.5 & $(4.6-12.5)$ & $<0.0001$ \\
$\begin{array}{l}\text { Third ventricle- } \\
\quad \text { abnormal (189) }\end{array}$ & 6.1 & $(4.5-13.5)$ & $<0.0001$ \\
$\begin{array}{l}\text { Basal mesencephalic } \\
\text { cisterns-abnormal (265) }\end{array}$ & 5.9 & $(3.6-9.5)$ & $<0.0001$ \\
\hline
\end{tabular}

OR, odds ratio; $\mathrm{CI}$, confidence interval. ref.

$7.6-(3.1-18.2)<0.0001$

ref.

$11.1 \quad(4.5-27.5) \quad<0.0001$

$21.3 \quad(4.5-101.2) \quad<0.0001$

ref.

$5.9 \quad(3.1-11.2) \quad<0.0001$

$14.1 \quad(5.2-38.5) \quad<0.0001$

ref.

$\begin{array}{rll}2.9 & (1.5-5.5) & <0.0001 \\ 24.1 & (9.0-64.7) & <0.0001\end{array}$

ref.

$\begin{array}{rlr}3.7 & (2.1-6.5) & <0.0001 \\ 34.2 & (11.9-97.8) & <0.0001\end{array}$

ref.

$4.5 \quad(2.3-8.7) \quad<0.0001$

$14.8 \quad(6.4-34.2) \quad<0.0001$

ref.

$2.0-(1.0-4.1) \quad 0.0100$

$15.5 \quad(6.8-35.5) \quad<0.0001$

ref.

$\begin{array}{lll}2.2 & (1.2-3.9) \quad 0.0010\end{array}$

$22.0 \quad(9.8-49.8) \quad<0.0001$

$<0.0001$ 
Table 5A. Association of Cistern and Ventricle Status (Trimodal) With DeAth $(\mathrm{N}=605)$ after Multivariate Analysis

\begin{tabular}{lccc}
\hline Cistern/ventricle & OR & $99 \% \mathrm{CI}$ & $\mathrm{p}$ \\
\hline Fourth ventricle & & & \\
Normal & ref. & & \\
Compressed & 3.3 & $(1.4-7.6)$ & $<0.0001$ \\
Absent & 4.5 & $(1.0-20.5)$ & 0.0110 \\
Ambient cisterns & & & \\
Normal & ref. & & \\
Compressed & 3.5 & $(1.9-6.6)$ & $<0.0001$ \\
Absent & 10.1 & $(3.9-26.4)$ & $<0.0001$ \\
\hline
\end{tabular}

OR, odds ratio; CI, confidence interval; ref., reference.

Table 5B. Association of Cistern and Ventricle Status (Bimodal) With Death $(\mathrm{N}=605)$ AfTER Multivariate ANAlysis

\begin{tabular}{lllc}
\hline Cistern/ventricle & OR & $99 \%$ CI & $\mathrm{p}$ \\
\hline Fourth ventricle-abnormal & 5.7 & $(2.8-11.6)$ & $<0.0001$ \\
Ambient cisterns-abnormal & 4.5 & $(2.5-8.1)$ & $<0.0001$ \\
\hline
\end{tabular}

OR, odds ratio; $\mathrm{CI}$, confidence interval.

Table 5C. Association of Cistern and Ventricle Status (Bi- ANd Trimodal) With DeAth $(\mathrm{N}=605)$ after Multivariate Analysis

\begin{tabular}{lrcc}
\hline Cistern/ventricle & OR & $99 \%$ CI & $\mathrm{p}$ \\
\hline Fourth ventricle-abnormal & 3.4 & $(1.5-7.8)$ & $<0.0001$ \\
Ambient cisterns & & & \\
Normal & ref. & & \\
Compressed & 3.5 & $(1.9-6.5)$ & $<0.0001$ \\
Absent & 10.8 & $(4.3-27.1)$ & $<0.0001$ \\
\hline
\end{tabular}

OR, odds ratio; $\mathrm{CI}$, confidence interval; ref., reference.

one single characteristic. Therefore the individual contribution of the third ventricle in the prediction of outcome is not clear, and may be inferior to that of the basal cisterns.

Whereas the mortality rate $(39 \%)$ and proportion of severe TBI patients with an unfavorable outcome (50\%) is largely in line with reports in the literature (Edwards et al., 2005; Cremer et al., 2006), the death rate of the moderate TBI patients $(23 \%)$ is relatively high. Several studies demonstrated lower mortality rates of 3-13\% (Edwards et al., 2005; Fabbri et al., 2008; Fearnside and McDougall, 1998; Murray et al., 1999; Rimel et al., 1982; Vitaz et al., 2003;), save for one recent study that found a higher rate of 33\% (Stranjalis et al., 2008). One possible explanation for the high mortality rate in our moderate TBI patients might be the secondary and tertiary referral function of our level I trauma center. This results from the transfer from adjacent hospitals of more severely injured moderate TBI patients, for instance patients with severe CT abnormalities at risk for deterioration or needing immediate neurosurgical intervention (and surgical intervention in cases of polytrauma). Also, some of the studies that found a lower mortality rate in moderate TBI included patients with a hos-
Table 6A. Association of Cistern and Ventricle Status (Trimodal) with Unfavorable Outcome $(\mathrm{N}=567)$ After Multivariate Analysis

\begin{tabular}{lrlc}
\hline Cistern/ventricle & OR & $99 \% \mathrm{CI}$ & $\mathrm{p}$ \\
\hline Ambient cisterns & & & \\
Normal & ref. & & \\
Compressed & 4.5 & $(2.5-8.1)$ & $<0.0001$ \\
Absent & 36.6 & $(11.9-112.7)$ & $<0.0001$ \\
\hline
\end{tabular}

OR, odds ratio; $\mathrm{CI}$, confidence interval; ref., reference.

Table 6B. Association of Cistern and Ventricle Status (Bimodal) With Unfavorable Outcome $(\mathrm{N}=567)$ After Multivariate Analysis

\begin{tabular}{lllc}
\hline Cistern/ventricle & OR & $99 \%$ CI & $\mathrm{p}$ \\
\hline Fourth ventricle-abnormal & 6.0 & $(2.2-13.5)$ & $<0.0001$ \\
Ambient cisterns-abnormal & 4.6 & $(2.5-8.4)$ & $<0.0001$ \\
\hline
\end{tabular}

OR, odds ratio; $\mathrm{CI}$, confidence interval.

Table 6C. Association of Cistern and Ventricle Status (BI- AND Trimodal) With Unfavorable Outcome $(\mathrm{N}=567)$ after Multivariate Analysis

\begin{tabular}{lrcc}
\hline Cistern/ventricle & OR & $99 \%$ CI & $\mathrm{p}$ \\
\hline Fourth ventricle-abnormal & 3.0 & $(1.1-8.2)$ & 0.006 \\
Cisterna ambiens & & & \\
Normal & ref. & & \\
Compressed & 3.6 & $(2.0-6.7)$ & $<0.0001$ \\
Absent & 16.3 & $(4.4-60.8)$ & $<0.0001$ \\
\hline
\end{tabular}

$\mathrm{OR}$, odds ratio; $\mathrm{CI}$, confidence interval; ref., reference.

pital admission GCS score of 13. It is well known that the case fatality rate in GCS 13 patients is lower than in GCS 9-12 patients. Although still debated, in many other studies of TBI, also from our institution, patients with a GCS score of 13 were classified as having mild TBI (Fearnside and McDougall, 1998; Smits et al., 2005; Stulemeijer et al., 2006; Fabbri et al., 2008).

Notwithstanding the fact that CT is already the diagnostic tool of choice in moderate and severe TBI, and that its prognostic value has been well established, the relative importance of CT in the prediction of outcome may have increased in recent years. This is related to the observed loss of predictive power of the GCS as a classic outcome predictor and determinant of TBI severity (Balestreri et al., 2004). Intensified prehospital treatments, comprised of early sedation and intubation, of trauma patients hampers valid neurological examination and results in erroneously low GCS scores (Balestreri et al., 2004). Nevertheless, in our study, the GCS was univariately associated with both death and unfavorable outcome. In the multivariate analyses this association was, however, lost.

Formal data on the inter- and intraobserver reliability of scoring individual cisterns and ventricles, particularly in TBI, are absent (The American Association of Neurological Surgeons, 2000). In a previous study we described the interrater and intrarater coefficients for the TCDB CT classification, but 


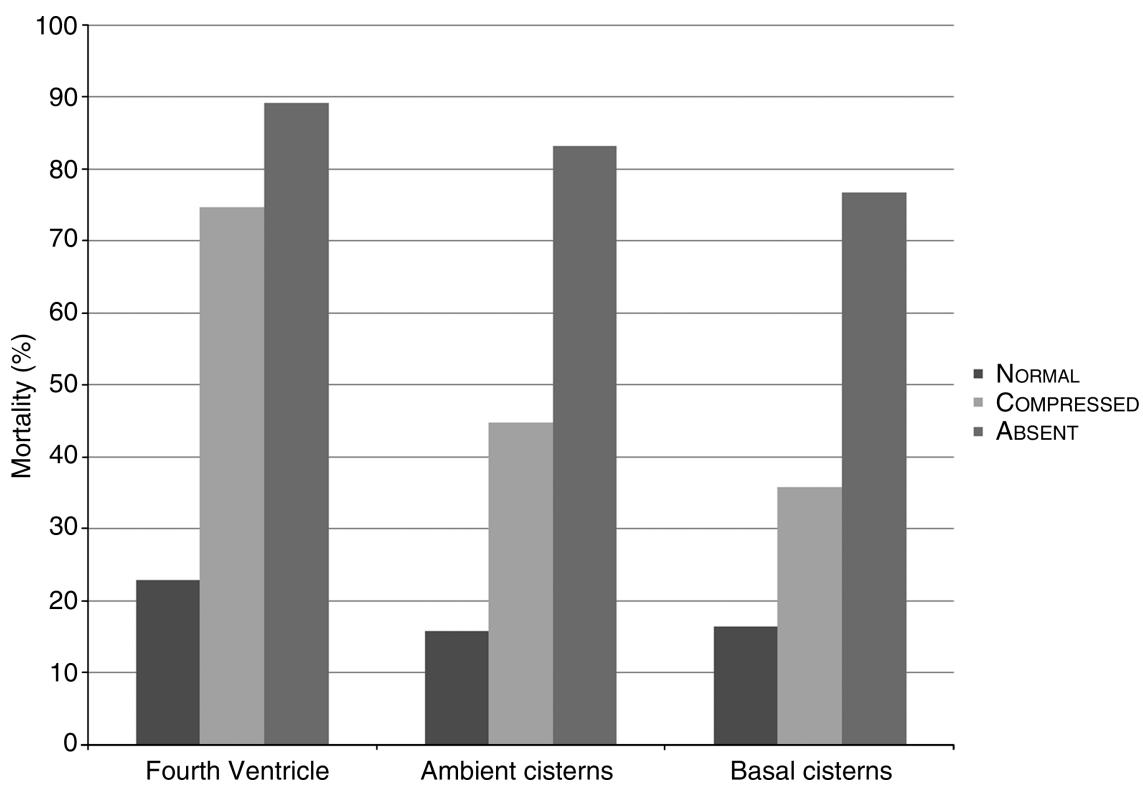

FIG. 3. Distribution of mortality rate differentiated by the status of the fourth ventricle, ambient cisterns, and the basal cisterns.

not for the individual CT characteristics, and demonstrated high reliability in the scoring of the different TCDB categories (Vos et al., 2001). Considering the significant role of the appearance of the basal cisterns in the TCDB CT classification, one might assume that the reliability of scoring the basal cisterns would show comparable coefficients. Nonetheless, both the interrater and intrarater kappa coefficients found in our current study are more than adequate (Landis and Koch, 1977).

\section{Limitations}

We are aware of some limitations of our study. The first limitation is due to the missing data in this prospective study. Because of missing relevant CT data, 21 patients $(3.0 \%)$ had to be excluded. Moreover, for some of the CT characteristics the percentage of missing values was up to $2.1 \%$ (aspect of the fourth ventricle, quadrigeminal cistern, sylvian fissures, and lateral ventricles). Additionally, not all included patients could be used for outcome prediction analysis. In the severe TBI group of 31 patients $(5.4 \%)$, only data on survival, but no adequate GOS-E scores were available, and 36 patients $(6.3 \%)$ were completely lost to follow-up, mainly due to the inclusion of patients from abroad that were unable to be present for follow-up consultations. For the moderate TBI patients, loss to follow-up was $13.5 \%(n=17)$, and for 7 patients $(5.6 \%)$ insufficient outcome data were registered to ascertain the GOS-E. The rate of loss to follow-up for the entire study was $7.6 \%$. In a recent review of prognostic models of TBI, less than $10 \%$ was considered an acceptable rate of loss to follow-up (Perel et al., 2006).

Secondly, this study was based on the acute CT characteristics of TBI (i.e., the first CT scan only). Severe, and to a lesser extent also moderate TBI, however, are dynamic pathological processes in which CT scans show changes that take place over time post-trauma. This has been demonstrated for traumatic intracerebral hematomas, brain swelling and edema, midline shift, and post-traumatic cerebral infarction
(Clifton et al., 1980; Cooper et al., 1979; Lobato et al., 1997; Narayan et al., 2008; Servadei et al., 2000); however, this has not been shown specifically for the status of cisterns and ventricles. The eventual outcome is more accurately predicted using data from sequential rather than initial CT scans (Lobato et al., 1997). Nevertheless, we think the findings of the initial CT scan remain important in clinical decision making and for prognostic purposes. Furthermore, these findings are also strongly associated with outcome after TBI (Maas et al., 2005, 2007).

\section{Conclusion}

In moderate and severe TBI, a combination of the status of ambient cisterns, as assessed with a simple 3-point score (normal, compressed, or absent), and the status of the fourth ventricle, described as either normal or abnormal, proved the most powerful predictors of outcome at 6 months post-injury. The currently most widely used parameter, the status of the basal perimesencephalic cisterns, was surpassed in predictive value, and therefore the ambient cisterns and the fourth ventricle may be considered good alternatives for use in CT prediction models. The assessment of the ambient cisterns and the fourth ventricle also had sufficient interrater and intrarater reliability.

\section{Author Disclosure Statement}

No competing financial interests exist.

\section{References}

Balestreri, M., Czosnyka, M., Chatfield, D.A., Steiner, L.A., Schmidt, E.A., Smielewski, P., Matta, B., and Pickard, J.D. (2004). Predictive value of Glasgow Coma Scale after brain trauma: change in trend over the past ten years. J. Neurol. Neurosurg. Psychiatry 75, 161-162.

Chen, R., Zhang, S., Zhang, W., Tan, L., Li, Q., and Zhao, H. (2009). A comparative study of thin-layer cross-sectional 
anatomic morphology and CT images of the basal cistern and its application in acute craniocerebral traumas. Surg. Radiol. Anat. 31, 129-138.

Choi, S.C., Barnes, T.Y., Bullock, R., Germanson, T.A., Marmarou, A., and Young, H.F. (1994). Temporal profile of outcomes in severe head injury. J. Neurosurg. 81, 169-173.

Clifton, G.L., Grossman, R.G., Makela, M.E., Miner, M.E., Handel, S., and Sadhu, V. (1980). Neurological course and correlated computerized tomography findings after severe closed head injury. J. Neurosurg. 52, 611-624.

Colquhoun, I.R. and Burrows, E.H. (1989). The prognostic significance of the third ventricle and basal cisterns in severe closed head injury. Clin. Radiol. 40, 13-16.

Cooper, P.R., Maravilla, K., Moody, S., and Clark, W.K. (1979). Serial computerized tomographic scanning and the prognosis of severe head injury. Neurosurgery 5, 566-569.

Cremer, O.L., Moons, K.G., van Dijk, G.W., van Balen, B.P., and Kalkman, C.J. (2006). Prognosis following severe head injury: Development and validation of a model for prediction of death, disability, and functional recovery. J. Trauma 61, 1484-1491.

Edwards, P., Arango, M., Balica, L., for the CRASH trial collaborators. (2005). Final results of MRC CRASH, a randomised placebo-controlled trial of intravenous corticosteroid in adults with head injury-outcomes at 6 months. Lancet 365, 1957-1959.

Eisenberg, H.M., Gary, H.E., Jr., Aldrich, E.F., Saydjari, C., Turner, B., Foulkes, M.A., Jane, J.A., Marmarou, A., Marshall, L.F., and Young, H.F. (1990). Initial CT findings in 753 patients with severe head injury. A report from the NIH Traumatic Coma Data Bank. J. Neurosurg. 73, 688-698.

Fabbri, A., Servadei, F., Marchesini, G., Stein, S.C., and Vandelli, A. (2008). Early predictors of unfavourable outcome in subjects with moderate head injury in the emergency department. J. Neurol. Neurosurg. Psychiatry 79, 567-573.

Fearnside, M. and McDougall, P. (1998). Moderate head injury: a system of neurotrauma care. Aust. N.Z. J. Surg. 68, 58-64.

Hukkelhoven, C.W., Rampen, A.J., Maas, A.I., Farace, E., Habbema, J.D., Marmarou, A., Marshall, L.F., Murray, G.D., and Steyerberg, E.W. (2006). Some prognostic models for traumatic brain injury were not valid 1. J. Clin. Epidemiol. 59, 132143.

Hukkelhoven, C.W., Steyerberg, E.W., Habbema, J.D., Farace, E., Marmarou, A., Murray, G.D., Marshall, L.F., and Maas, A.I. (2005). Predicting outcome after traumatic brain injury: development and validation of a prognostic score based on admission characteristics. J. Neurotrauma 22, 1025-1039.

Jacobs, B., Beems, T., Stulemeijer, M., van Vugt, A.B., van der Vliet T.M., Borm, G.F., and Vos, P.E. (2009). Outcome prediction in mild traumatic brain injury: age and clinical variables are stronger predictors than CT abnormalities. J Neurotrauma (epub ahead of print).

Landis, J.R. and Koch, G.G. (1977). The measurement of observer agreement for categorical data. Biometrics 33, 159-174.

Lannoo, E., Van Rietvelde, F., Colardyn, F., Lemmerling, M., Vandekerckhove, T., Jannes, C., and De Soete, G. (2000). Early predictors of mortality and morbidity after severe closed head injury. J. Neurotrauma 17, 403-414.

Liu, H.M., Tu, Y.K., and Su, C.T. (1995). Changes of brainstem and perimesencephalic cistern: dynamic predictor of outcome in severe head injury. J. Trauma 38, 330-333.

Lobato, R.D., Gomez, P.A., Alday, R., Rivas, J.J., Dominguez, J., Cabrera, A., Turanzas, F.S., Benitez, A., and Rivero, B. (1997). Sequential computerized tomography changes and related final outcome in severe head injury patients. Acta Neurochir. 139, 385-391.
Maas, A.I., Hukkelhoven, C.W., Marshall, L.F., and Steyerberg, E.W. (2005). Prediction of outcome in traumatic brain injury with computed tomographic characteristics: a comparison between the computed tomographic classification and combinations of computed tomographic predictors. Neurosurgery 57, 1173-1182.

Maas, A.I., Steyerberg, E.W., Butcher, I., Dammers, R., Lu, J., Marmarou, A., Mushkudiani, N.A., McHugh, G.S., and Murray, G.D. (2007). Prognostic value of computerized tomography scan characteristics in traumatic brain injury: results from the IMPACT study. J. Neurotrauma 24, 303-314.

Marmarou, A., Lu, J., Butcher, I., McHugh, G.S., Mushkudiani, N.A., Murray, G.D., Steyerberg, E.W., and Maas, A.I. (2007). IMPACT database of traumatic brain injury: design and description. J. Neurotrauma 24, 239-250.

Marshall, L.F., Eisenberg, H.M., Jane, J.A., Luerssen, T.G., Marmarou, A., and Foulkes, M.A. (1991). A new classification of head injury based on computerized tomography. J. Neurosurg. 75, s14-s20.

Metting, Z., Rodiger, L.A., de Keyser, J., and van der Naalt, J. (2007). Structural and functional neuroimaging in mild-tomoderate head injury. Lancet Neurol. 6, 699-710.

Murray, G.D., Butcher, I., McHugh, G.S., Lu, J., Mushkudiani, N.A., Maas, A.I., Marmarou, A., and Steyerberg, E.W. (2007). Multivariable prognostic analysis in traumatic brain injury: results from the IMPACT study. J. Neurotrauma 24, 329-337.

Murray, G.D., Teasdale, G.M., Braakman, R., on behalf of the European Brain Injury Consortium. (1999). The European Brain Injury Consortium survey of head injuries. Acta Neurochir. 141, 223-236.

Narayan, R.K., Maas, A.I., Servadei, F., Skolnick, B.E., Tillinger, M.N., and Marshall, L.F. (2008). Progression of traumatic intracerebral hemorrhage: a prospective observational study. J. Neurotrauma 25, 629-639.

Perel, P., Arango, M., Clayton, T., Edwards, P., Komolafe, E., Poccock, S., Roberts, I., Shakur, H., Steyerberg, E., and Yutthakasemsunt, S. (2008). Predicting outcome after traumatic brain injury: practical prognostic models based on large cohort of international patients. B.M.J. 336, 425-429.

Perel, P., Edwards, P., Wentz, R., and Roberts, I. (2006). Systematic review of prognostic models in traumatic brain injury. B.M.C. Med. Inform. Decis. Mak. 6, 38.

Rimel, R.W., Giordani, B., Barth, J.T., and Jane, J.A. (1982). Moderate head injury: completing the clinical spectrum of brain trauma. Neurosurgery 11, 344-351.

Selladurai, B.M., Jayakumar, R., Tan, Y.Y., and Low, H.C. (1992). Outcome prediction in early management of severe head injury: an experience in Malaysia. Br. J. Neurosurg. 6, 549-557.

Servadei, F., Murray, G.D., Penny, K., Teasdale, G.M., Dearden, M., Iannotti, F., Lapierre, F., Maas, A.J., Karimi, A., Ohman, J., Persson, L., Stocchetti, N., Trojanowski, T., and Unterberg, A. (2000). The value of the "worst" computed tomographic scan in clinical studies of moderate and severe head injury. European Brain Injury Consortium. Neurosurgery $46,70-75$.

Signorini, D.F., Andrews, P.J., Jones, P.A., Wardlaw, J.M., and Miller, J.D. (1999a). Adding insult to injury: the prognostic value of early secondary insults for survival after traumatic brain injury. J. Neurol. Neurosurg. Psychiatry 66, 26-31.

Signorini, D.F., Andrews, P.J., Jones, P.A., Wardlaw, J.M., and Miller, J.D. (1999b). Predicting survival using simple clinical variables: a case study in traumatic brain injury. J. Neurol. Neurosurg. Psychiatry 66, 20-25. 
Smits, M., Dippel, D.W., de Haan, G.G., Dekker, H.M., Vos, P.E., Kool, D.R., Nederkoorn, P.J., Hofman, P.A., Twijnstra, A., Tanghe, H.L., and Hunink, M.G. (2005). External validation of the Canadian CT Head Rule and the New Orleans Criteria for CT scanning in patients with minor head injury. JAMA 294, $1519-1525$.

Steyerberg, E.W., Mushkudiani, N., Perel, P., Butcher, I., Lu, J., McHugh, G.S., Murray, G.D., Marmarou, A., Roberts, I., Habbema, J.D., and Maas, A.I. (2008). Predicting outcome after traumatic brain injury: development and international validation of prognostic scores based on admission characteristics. PLoS. Med. 5, e165.

Stranjalis, G., Bouras, T., Korfias, S., Andrianakis, I., Pitaridis, M., Tsamandouraki, K., Alamanos, Y., Sakas, D.E., and Marmarou, A. (2008). Outcome in 1,000 head injury hospital admissions: the Athens head trauma registry. J. Trauma 65, 789-793.

Stulemeijer, M., van der Werf, S.P., Jacobs, B., Biert, J., van Vugt, A.B., Brauer, J.M., and Vos, P.E. (2006). Impact of additional extracranial injuries on outcome after mild traumatic brain injury. J. Neurotrauma 23, 1561-1569.

Teasdale, E., Cardoso, E., Galbraith, S., and Teasdale, G.M. (1984). CT scan in severe diffuse head injury: physiological and clinical correlations. J. Neurol. Neurosurg. Psychiatry 47, 600-603.

The American Association of Neurological Surgeons. The Brain Trauma Foundation. The Joint Section on Neurotrauma and Critical Care. (2000). Computed tomography scan features. J. Neurotrauma 17, 597-627.

Toutant, S.M., Klauber, M.R., Marshall, L.F., Toole, B.M., Bowers, S.A., Seelig, J.M., and Varnell, J.B. (1984). Absent or compressed basal cisterns on first CT scan: ominous predictors of outcome in severe head injury. J. Neurosurg. 61, 691-694.

van Dongen, K.J., Braakman, R., and Gelpke, G.J. (1983). The prognostic value of computerized tomography in comatose head-injured patients. J. Neurosurg. 59, 951-957.

Vitaz, T.W., Jenks, J., Raque, G.H., and Shields, C.B. (2003). Outcome following moderate traumatic brain injury. Surg. Neurol. 60, 285-291.

Vos, P.E., van Voskuilen, A.C., Beems, T., Krabbe, P.F., and Vogels, O.J. (2001). Evaluation of the traumatic coma data bank computed tomography classification for severe head injury. J. Neurotrauma 18, 649-655.

Wardlaw, J.M., Easton, V.J., and Statham, P. (2002). Which CT features help predict outcome after head injury? J. Neurol. Neurosurg. Psychiatry 72, 188-192.

Wilson, J.T., Pettigrew, L.E., and Teasdale, G.M. (1998). Structured interviews for the Glasgow Outcome Scale and the extended Glasgow Outcome Scale: guidelines for their use. J. Neurotrauma 15, 573-585.

Address correspondence to:

Pieter E. Vos, M.D., Ph.D. Radboud University Nijmegen Medical Centre

Department of Neurology (935)

P.O. Box 9101

6500 HB Nijmegen, The Netherlands

E-mail: p.vos@neuro.umcn.nl 